\title{
Mild Traumatic Brain Injury in Mice Beneficially Alters Lung NK1R and Structural Protein Expression to Enhance Survival after Pseudomonas aeruginosa Infection
}

\author{
Max Vaickus, Terry Hsieh, Ekaterina Kintsurashvili, Jiyoun Kim, Daniel Kirsch, George Kasotakis, and Daniel G. Remick
}

From the Department of Pathology and Laboratory Medicine, Boston University School of Medicine, Boston, Massachusetts

\author{
Accepted for publication \\ October 23, 2018. \\ Address correspondence to \\ Daniel G. Remick, M.D., 670 \\ Albany St., 4th Floor, Boston, \\ MA 02118. E-mail: remickd@ \\ bu.edu.
}

\begin{abstract}
Mild traumatic brain injury (mTBI) in a murine model increases survival to a bacterial pulmonary challenge compared with blunt tail trauma (TT). We hypothesize substance $P$ and its receptor, the neurokinin 1 receptor (NK1R; official name TACR1), play a role in the increased survival of mTBI mice. Mice were subjected to mTBI or TT, and 48 hours after trauma, the levels of NK1R mRNA and protein were significantly up-regulated in mTBI lungs. Examination of the lung 48 hours after injury by microarray showed significant differences in the expression of 433 gene sets between groups, most notably genes related to intercellular proteins. Despite down-regulated gene expression of connective proteins, the presence of an intact pulmonary vasculature was supported by normal histology and bronchoalveolar lavage protein levels. To determine whether these mTBI-induced lung changes benefited in vivo responses, two chemotactic stimuli (a CXCL1 chemokine and a live Pseudomonas aeruginosa infection) were administered 48 hours after trauma. For both stimuli, mTBI mice recruited more neutrophils to the lung 4 hours after instillation (CXCL1: $\mathrm{mTBI}=6.3 \pm 1.3$ versus TT $=3.3 \pm 0.7$ neutrophils $/ \mathrm{mL}$; Pseudomonas aeruginosa: $\mathrm{mTBI}=9.4 \pm 1.4$ versus TT $=5.3 \pm 1.1$ neutrophils $/ \mathrm{mL}$ ). This study demonstrates that the downstream consequences of mTBI on lung NK1R levels and connective protein expression enhance neutrophil recruitment to a stimulus that may contribute to increased survival. (Am J Pathol 2019, 189: 295-307; https://doi.org/10.1016/j.ajpath.2018.10.019)
\end{abstract}

Traumatic brain injury (TBI) is a serious global health issue responsible for close to 2.5 million emergency department visits per year. ${ }^{1}$ Both TBI and mild TBI (mTBI), which is the focus of this study, can trigger a series of complicated physiological events such as cerebral metabolic alterations and the stimulation of inflammatory and immunological responses. $^{2,3}$ Following injury, recruitment of immune and glial cells to the site of trauma is increased by up-regulation of the cell adhesion molecules P-selectin, intercellular adhesion molecule 1 , and vascular cell adhesion molecule $1 .^{2}$ The local infiltration of leukocytes is aided by the release of proinflammatory cytokines, including tumor necrosis factor, IL-1 $\beta$, and IL- 6 shortly after injury. ${ }^{4}$ These cytokines can initiate a cascade of events downstream of the mTBI, resulting in systemic alterations in the host. However, the full range of the repercussions of a mTBI and their mechanisms are still relatively unknown.

Previous studies show that injury stimulates the innate immune response ${ }^{5}$ and that mice with a previous burn injury have decreased mortality to a subsequent Escherichia coliinduced sepsis. ${ }^{6}$ A model of pulmonary contusion showed that mice with a previous injury had decreased mortality to a subsequent Pseudomonas aeruginosa (Psd) infection. ${ }^{7}$ Although counterintuitive, these prior two-hit injury studies support the authors' laboratory's previous work that $\mathrm{mTBI}$ in both patients and a murine model of mTBI reduced

Supported by NIH grants RO1GM117519, T32GM86308, R21AA022122, R21AI112887, and UL1-TR001430.

Disclosures: None declared. 
mortality rates compared with trauma controls when infected with Psd. ${ }^{8,9}$ The mechanisms of the downstream mTBI beneficial effects are still under investigation, although some pathways have been described.

One beneficial response of mTBI investigated in previous studies ${ }^{8,9}$ suggests that substance $\mathrm{P}(\mathrm{SP})$ plays an important role in augmenting the immune response after mTBI. SP is an 11-amino acid neuropeptide that acts through the tachykinin neurokinin-1 receptor (NK1R; official name TACR1). It is believed that following mTBI, SP is released and acts on the NK1Rs throughout the organism. Other neurokinin receptors exist (NK2R and NK3R), and depending on concentrations of SP and receptor availability, SP can act through them. However, SP acts preferentially on NK1R. ${ }^{10} \mathrm{SP}$ is known to recruit inflammatory cells into tissues either through its effect on the tissue's NK1Rs (vasodilation) or the inflammatory cell's NK1Rs (chemotaxis). ${ }^{11}$ The chemotactic properties of SP for neutrophils and other immune responders has been well documented. ${ }^{12-14}$ The hypothesis for the role of released SP from the mTBI acting on the NK1Rs throughout the mouse to enhance survival is supported by NK1R agonist and antagonist studies. ${ }^{9}$ When the mTBI mice were treated with a highly specific NK1R antagonist and then challenged with bacteria, the increased survival effect was eliminated, supporting the importance of the NK1R and its ligand SP as principal mediators of the increased survival. However, despite the support of the NK1R agonist and antagonist studies, levels of SP in the bronchoalveolar lavage (BAL) and plasma are equivalent within 90 minutes between the mTBI and TT mice. Shortly after trauma, it appears that the amount of SP released between groups is not the sole factor influencing the augmented immune response of mTBI mice. Although previous work in the authors' laboratory explored the role of SP in this augmented immune response, ${ }^{8,9}$ this study aims to identify any beneficial alterations the mTBI may have on the site of infection versus TT at the point immediately prior to the pathogenic insult.

\section{Materials and Methods}

\section{Animals}

Female ICR (CD-1) mice (Harlan Laboratories, Frederick, MD) were used in all experiments. Mice could access food and water ad libitum for the entire study. Animals were housed in a room set on a diurnal 12-hour light/dark cycle that was temperature and humidity controlled. Mice were allowed to acclimate for at least 72 hours before any experiments. All mice weighed 23 to $30 \mathrm{~g}$ and were at least 8 to 10 weeks old. All experiments were approved by the Boston University Institutional Animal Care and Use Committee.

\section{Brain Injury and Trauma Model}

mTBI was performed as previously described. ${ }^{8,9}$ Under isoflurane anesthesia, mice were placed prone on an acrylic bed with their head resting on a foam pad under a 170 -g steel rod encased in a guide tube. The rod is dropped from $5.2 \mathrm{~cm}$ above the skull to impact a point in the midline of the skull, producing a $5 \mathrm{~kg} / \mathrm{cm}^{2}$ impact force halfway between the interauricular and interorbital lines. Rebound impact is prevented, and mice were immediately injected subcutaneously with $0.05 \mathrm{mg} / \mathrm{kg}$ buprenorphine in $1 \mathrm{~mL}$ of warmed normal saline. Mice were placed supine on a warming bed until able to right themselves. The control trauma model, tail trauma (TT), was performed as previously described. ${ }^{8}$ TT was induced by placing isofluraneanesthetized mice in a prone position under the weightdrop mTBI apparatus. The 170-g rod was dropped from a height of $8.5 \mathrm{~cm}$ on the tail $2 \mathrm{~cm}$ from the base. TT mice received the same buprenorphine dose and were placed on the warming bed before returning to their cages after righting themselves. Weights were recorded on the day of trauma, 24 hours, and 48 hours after trauma. Naive mice were anesthetized and placed on the trauma apparatus but did not receive any trauma. For some experiments in which naive mice were studied, these mice did not have any injury or anesthesia. Mice were only studied 48 hours after injury because this is the time interval when patients are most likely to develop pneumonia.

\section{RNA Extraction}

Mice were anesthetized with isoflurane, xylazine/ketamine, and exsanguinated via retro-orbital bleeding. All mice underwent BAL with $1 \mathrm{~mL}$ of a 50:1 Hanks' balanced salt solution/EDTA mixture (169 mmol/L EDTA). The lavage fluid was spun, and the supernatant was frozen for later analysis. After BAL, two random sections of the right lung were sampled from the superior and inferior lobe of each mouse to introduce randomization and heterogeneity of the tissue sample collected. The left lung was perfused with $70 \%$ ethanol as previously described ${ }^{15}$ and removed for later histology or was snap-frozen in liquid nitrogen for later protein extraction. The right-lung sections were stored in RNAlater (Thermo Fisher Scientific, Waltham, MA) overnight. RNA to be sent to the Boston University Microarray Core was extracted as follows. After RNAlater fixation, a section from each of the two lung samples were placed in $600 \mu \mathrm{L}$ of Buffer RLT (Qiagen, Hilden, Germany) with $6 \mu \mathrm{L}$ of 14.3 $\mathrm{mol} / \mathrm{L}$ beta-mercaptoethanol (Sigma, St. Louis, MO) then homogenized using the TissueLyser II at $30 \mathrm{~Hz}$ for $4 \mathrm{mi}-$ nutes. RNA was then extracted from the homogenate using the QiaCube equipped with the RNeasy Plus Mini Kit.

\section{Real-Time qPCR}

Total RNA was extracted from the RNAlater-preserved right lung using RNAeasy RNA extraction kit (Qiagen, Germantown, MD) as suggested by the manufacturer. The RNA concentration was measured using a NanoDrop 2000C spectrophotometer (Thermo Fisher Scientific). cDNA synthesis and real-time quantitative PCR (qPCR) was 
Table 1 Primers Used for Quantitative Real-Time PCR

\begin{tabular}{lll}
\hline Primer & Forward sequence & Reverse sequence \\
\hline NK-1R & $5^{\prime}$-GATACCTCCAGACCCAGA-3' & $5^{\prime}$-GCTGGAGCTTTCTGTCATG-3' \\
HPRT & $5^{\prime}$-TGACACTGGCAAAACAATGCA-3' & $5^{\prime}$-GGTCCTTTTCACCAGCAAGCT-3' \\
VE-cadherin ${ }^{16}$ & $5^{\prime}$-ACGGACAAGATCAGCTCCTC-3' & $5^{\prime}-$ TCTCTTCATCGATGTGCATT-3' \\
16S rRNA & $5^{\prime}$-AGAGTTTGATCCTGGCTCAG-3' & $5^{\prime}$-ACGGCTACCTTGTTACGACTT-3' \\
\hline
\end{tabular}

HPRT, hypoxanthine-guanine phosphoribosyltransferase.

performed using Luna Universal One-Step Real-Time qPCR kit (NEB, Boston, MA) and a Bio-Rad iQ5 (Bio-Rad Laboratories, Hercules, CA) real-time PCR system. Primers for quantitative real-time PCR were synthesized by Integrated DNA Technologies (Coralville, IA) and are listed in Table $1 .{ }^{16}$ Real-time qPCR was performed using $100 \mathrm{ng}$ of total RNA in reaction setup (total volume of $20 \mu \mathrm{L}$ ) as suggested by the manufacturer (NEB). Cycling included 10 minutes of reverse transcription $\left(55^{\circ} \mathrm{C}\right), 1$-minute initial denaturation $\left(95^{\circ} \mathrm{C}\right), 40$ cycles of 10 seconds denaturation $\left(95^{\circ} \mathrm{C}\right)$, and 30 seconds extension $\left(60^{\circ} \mathrm{C}\right)$ for 10 seconds. The specificity of the PCR products was verified by the melting temperature and electrophoresis gel. The relative gene expression ratios were normalized to hypoxanthineguanine phosphoribosyltransferase (HPRT) or 16srRNA gene expression.

\section{Microarray}

General Procedure, Normalization, and Quality Assessment Gene microarray analysis was run on a mouse Affymetrix GeneChip Gene 1.0ST Array System with the help of the Boston University Microarray Core. All microarray analyses were performed using the $\mathrm{R}$ environment for statistical computing software version 2.15.1 (R Foundation for Statistical Computing, Vienna, Austria). Mouse Gene 1.0 ST CEL files were normalized to produce gene-level expression values using the implementation of the Robust Multiarray Average ${ }^{17}$ in the affy $\mathrm{R}$ package software version $1.36 .1^{18}$ included in the Bioconductor software suite version $2.12^{19}$ and an Entrez Gene-specific probeset mapping version 17.0.0 from the Molecular and Behavioral Neuroscience Institute (Brainarray) at the University of Michigan (Brainarray, http://brainarray. mbni.med.umich.edu/Brainarray/Database/CustomCDF, last accessed July 3, 2018). ${ }^{20}$ Array quality was assessed by computing relative log expression and normalized unscaled standard error using the affyPLM software package version 1. 34.0. ${ }^{21}$ Relative $\log$ expression is a measure of the relative quality of each sample (how much the signal was artificially boosted during normalization) compared with other arrays in the batch. Normalized unscaled standard error is a measure of the relative agreement between a sample's probes for each gene, compared with the other arrays in the batch. For each sample, median relative $\log$ expression values $>0.1$ or normalized unscaled standard error values $>1.05$ are considered out of usual limits. All arrays had median relative log expression and normalized unscaled standard error values within these limits, suggesting samples of similar quality. principal component analysis (PCA) was performed using the prcomp $\mathrm{R}$ function with values normalized across all samples to a mean of zero and a standard deviation of one. Differential expression was assessed using the moderated (empirical Bayesian) $t$-test implemented in the limma R software package version 3.14.4 (R Foundation, Vienna, Austria; www. bioconductor.org). Correction for multiple hypothesis testing was accomplished using the Benjamini-Hochberg false discovery rate (FDR). ${ }^{22}$ Human homologs of mouse genes were identified using HomoloGene software version $68 .^{23}$ The raw data can be accessed in the NCBI Gene Expression Omnibus site (https://www.ncbi.nlm.nih.gov/geo; accession number GSE120326).

\section{Positive Control Gene Expression}

The expression of several sex-specific genes (Xist, Ddx3y, Eif2s3y, Kdm5d, and Uty) was assessed to estimate the dynamic range of the array, because the female-specific marker Xist and constitutively expressed Y-linked genes serve as strong positive and negative expression controls in female animals, respectively (and vice versa in male animals). In all samples, the expression of Xist was high (approximately $9 \log _{2}$ units), and the expression of the Y-linked genes was very low (approximately 2 to $3 \log _{2}$ units), confirming that the mice used were female. This analysis also indicates that the experiment has good dynamic range to identify genes with true differential gene expression.

\section{Microarray Statistical Analysis}

Pairwise $t$-tests were performed for each gene between experimental groups to obtain a t statistic and $P$ value for each gene. A moderated $t$-test was used, which is a Bayesian analysis that does not test each gene independently, but rather, leverages information from all of the genes on the array to increase statistical power over the two-sample $t$-test. It was used because it is a helpful statistical analysis when sample sizes are small, as in this study. FDR correction was applied to obtain FDR-corrected $P$ values (q values). The FDR q value was also recomputed after removing genes that were not expressed above the array-wise median value of at least one array. Genes with low overall expression are more strongly affected by random technical variation and more likely to produce false-positive results. The value considered significant for the FDR q value (comparable to a $P<0.05)$ is $<0.25$. Q values represent the probability that a given result is a false positive based on the distribution of all 
$P$ values on the array. This implies that there is less than a $25 \%$ chance that the observed pattern between experimental groups is a false positive. Corrected/adjusted $P$ values such as the FDR $q$ are the best measure of significance for a given test when many genes are tested at once. All FDR q values mentioned will be $<0.25$, which is a good measure of significance given the breadth and sheer number of gene expression values that are factored into the FDR q value.

\section{GSEA}

Gene Set Enrichment Analysis (GSEA) software version 2.2.1 $1^{24}$ was used to identify biological terms, pathways, and processes that are coordinately up- or down-regulated within each pairwise comparison. The Entrez Gene identifiers of the human homologs of the genes interrogated by the array were ranked according to the moderated $t$ statistic computed between mTBI and TT. Mouse genes with multiple human homologs (or vice versa) were removed prior to ranking, so the ranked list represents only those human genes that match one mouse gene. This ranked list was then used to perform pre-ranked GSEA analyses (default parameters with random seed 1234) using the Entrez Gene versions of the Hallmark, Biocarta, KEGG, Reactome, Gene Ontology, and transcription factor and microRNA motif gene sets obtained from the Molecular Signatures Database version 5.0. ${ }^{25}$

\section{Western Blot}

Snap-frozen lung tissue was processed in a glass homogenizer with $600 \mu \mathrm{L}$ of radioimmunoprecipitation assay buffer (50 $\mathrm{mL}$ of radioimmunoprecipitation assay buffer $=50$ $\mathrm{mmol} / \mathrm{L}$ Tris HCL, $150 \mathrm{mmol} / \mathrm{L} \mathrm{NaCl}$, NP-40 1\%, SDS 1\%, $5 \mathrm{mmol} / \mathrm{L}$ EDTA, water to $50 \mathrm{~mL}$ ) and protease inhibitor (Roche, Indianapolis, IN). The homogenate was chilled on ice for 10 minutes then spun at $16,100 \times g$ at $4^{\circ} \mathrm{C}$ for 10 minutes. The supernatant was collected and tested for protein concentration using Bradford reagents and a bovine serum albumin standard (Bio-Rad, Hercules, CA). A total of $40 \mu \mathrm{g}$ of protein was mixed with $10 \mu \mathrm{L}$ of $4 \times$ SDS-Sample buffer (Boston Bioproducts, Ashland, MA), boiled at $100^{\circ} \mathrm{C}$ for 5 minutes, and then immediately put on ice for 2 minutes. Samples were loaded, and the gel was run at 95 volts for 15 minutes, then 125 volts for another hour. The gel was transferred at $0.4 \mathrm{~A}$ at $4^{\circ} \mathrm{C}$ for 2 hours. The membrane was blocked for 1 hour in Odyssey Blocking Buffer (Li-Cor, Lincoln, NE) followed by primary antibody incubation. Primary antibodies used for NK1R (SAB4502913; Sigma), VEcadherin (ab33168; Abcam, Cambridge, MA), and laminin (ab11575; Abcam) were incubated for a minimum of 1 hour at a 1:10,000 dilution. After washing, a secondary antibody (IRDye 680 RD goat anti-rabbit; Li-Cor), incubation for 1 hour was performed followed by a final wash. The membranes were imaged using an Odyssey near-infrared scanner (Li-Cor). Glyceraldehyde-3-phosphate dehydrogenase (GAPDH) (sc-32233; Santa Cruz Biotechnology, Dallas, TX) was used as a protein control using the same procedure and developed using an IRDye 680 LT goat anti-mouse (Li-Cor) secondary antibody at a 1:10,000 dilution.

For each protein (NK1R, VE-cadherin, laminin), three separate extractions and Western blots were performed. The result for each protein is averaged after quantification. Quantification of blotted bands (for Western blot and SDS page) was performed on digital images of the entire membrane using ImageJ software version 1.50i (NIH, Bethesda, MD; http:// imagej.nih.gov/ij). The digitized image was converted to black and white, and quantification of the protein levels was performed using the ImageJ Analyze gel function.

\section{Pulmonary Challenge with Bacteria or Chemokines}

Mice were administered $5 \times 10^{7}$ colony-forming units of Pseudomonas aeruginosa (Boston 41501; ATCC, Manassas, VA) in $50 \mu \mathrm{L}$ of Hank's balanced salt solution by intratracheal instillation 48 hours after trauma, as previously described. ${ }^{8,9}$ Mice were sacrificed 4 hours after infection under ketamine/xylazine anesthesia, and BAL was performed as previously described. ${ }^{8} \mathrm{~A}$ total of $5 \mathrm{~mL}$ of Hanks' balanced salt solution/EDTA (50:1) was used to lavage. The first $1 \mathrm{~mL}$ and remaining $4 \mathrm{~mL}$ were collected in separate tubes. Onehundred microliters of the first milliliter were serially diluted and plated for bacterial burden. Both tubes were spun and pellets were combined for cell count by a BeckmanCoulter particle counter (Coulter Electronics, Danvers, MA), and a differential was performed by counting 300 cells from a Cytospin (Shandon, Waltham, MA). Slides were stained with Diff-Quick (Siemens, Newark, DE). Mice used to determine peripheral blood bacterial burden underwent the same infection and sacrifice process but instead had $500 \mu \mathrm{L}$ of blood collected from the posterior vena cava with a 3.8\% citric acid-coated 22-G needle with a 1.0-mL syringe. Blood was serially diluted and plated on blood agar plates to determine colony-forming unit levels in the bloodstream. A separate set of mice underwent trauma and, 48 hours later, were intratracheally administered $500 \mathrm{ng}$ of a mouse CXCL1 (KC) chemokine (Peprotech, Rocky Hill, NJ) in $25 \mu \mathrm{L}$ of Hank's balanced salt solution. BAL was performed to determine neutrophil numbers by cytospin differential 4 hours after instillation of KC. Another set of mice had the same procedure performed without administration of $\mathrm{KC}$ or Psd to determine whether mTBI recruits more cells to the airspace without a stimulus 48 hours after injury. A final set of mice received mTBI or TT and, 48 hours after trauma, without pneumonia or $\mathrm{KC}$ instillation, were sacrificed and had a BAL performed as noted above. The supernatant of the first milliliter was frozen and stored for later protein analysis to assess any changes to lung integrity from the trauma.

\section{Histology}

Naive mice, as well as those receiving mTBI and TT as described, were sacrificed 48 hours after trauma. The lungs 

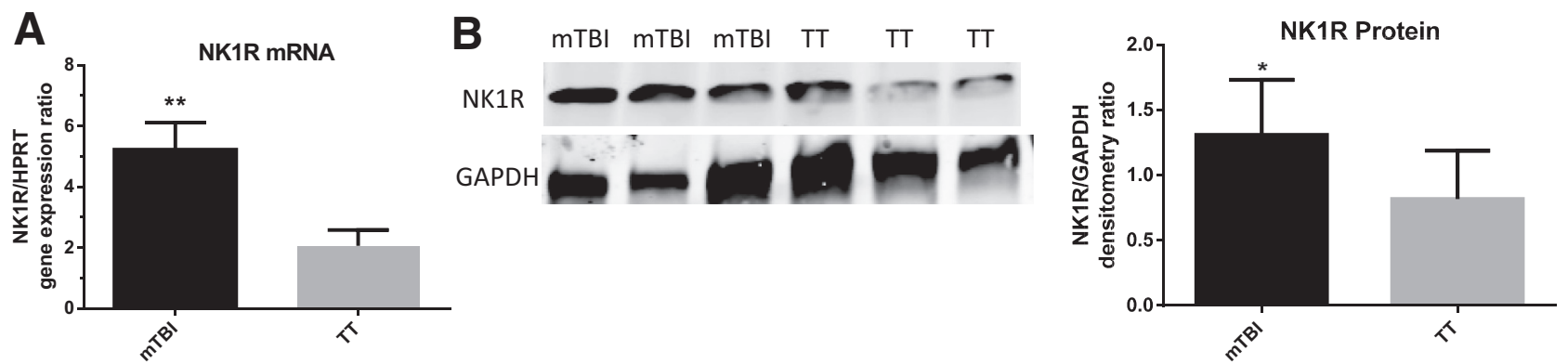

Figure 1 A: Pulmonary neurokinin 1 receptor (NK1R) gene expression. In mild traumatic brain injury (mTBI) and blunt tail trauma (TT) lungs 48 hours after trauma, NK1R gene expression is significantly up-regulated in mTBI lungs. B: NK-1R protein expression. Quantification of lung protein intensity relative to GAPDH 48 hours after trauma. The up-regulated NK1R gene expression seen in $\mathbf{A}$ is confirmed because the protein levels are significantly up-regulated in mTBI lungs. Data are expressed as means \pm SEM. $n=5 \mathrm{mTBI}(\mathbf{A}) ; n=7 \mathrm{TT}(\mathbf{A}) ; n=8 \mathrm{mTBI}$ and TT (B). ${ }^{*} P<0.05,{ }^{* *} P<0.01$ versus TT (unpaired two-tailed $t$-test).

were insufflated with $70 \%$ ethanol as previously described ${ }^{15}$ and sent for processing and paraffin embedding at Boston University's EX+ histology core. Lung damage was based on a blinded analysis by a board-certified pathologist (D.G.R.) on $5-\mu \mathrm{m}-$ thick hematoxylin and eosin-stained slides.

\section{Protein Analysis of BAL Fluid}

The supernatant of the first $1 \mathrm{~mL}$ of BAL collected 48 hours after trauma from mTBI, TT, and naive mice was analyzed for proteins of varying size.

\section{IgM and IgG ELISA}

IgM and IgG levels in BAL were determined by enzymelinked immunosorbent assay (ELISA) using antibodies purchased from BethylLab (Montgomery, TX) as described in the authors' previous publication. ${ }^{15}$

\section{Albumin ELISA}

Albumin levels in BAL were determined by ELISA. Borate buffer was used to dilute standards and solutions, and incubated overnight. The plate was blocked, and a rabbit anti-mouse albumin capture antibody was incubated for an hour. Following washing, a goat anti-rabbit $\operatorname{IgG}$ horseradish peroxidase was incubated for an hour. The plate was developed and read at $465 \mathrm{~nm}$ and $590 \mathrm{~nm}$.

\section{Statistics}

Groups were compared with the appropriate statistical tests described in the figure legends using GraphPad software version 6 (GraphPad Software, San Diego, CA).

\section{Results}

mTBI Lungs Have Increased NK1R Gene Expression and Protein Levels 48 Hours after Trauma

The authors' previous work ${ }^{8,9}$ hypothesized that SP plays a key role in the augmented immune response and increased survival of mTBI mice after pneumonia challenge.
However, the levels of SP were not significantly different in the BAL and serum shortly after mTBI or TT. There are many possibilities explaining this counterintuitive finding. A potential explanation supporting SP's role in immune augmentation despite similar levels as TT would be the upregulation of pulmonary expression of NK1R, so that response to the same levels of SP could be amplified. Total RNA was extracted from lungs 48 hours after trauma and the level of NK1R mRNA analyzed via real-time qPCR. mTBI lungs had a significantly higher gene expression of NK1R compared with TT lungs (Figure 1A). The protein levels of NK1R were analyzed in the lungs 48 hours after trauma via Western Blot to see whether the up-regulation of gene expression translated into higher protein levels, a pattern that has been documented. ${ }^{26}$ The mTBI lungs had significantly higher levels of NK1R protein compared with TT (Figure 1B). To rule out whether increased pulmonary cell recruitment could account for the increased NK1R mRNA and protein levels, BAL was performed at 48 hours after trauma on a separate set of mice. There was no significant difference in cell numbers in the TT or mTBI mice after injury (Table 2). Additionally, $1 \mathrm{~mL}$ of BAL was collected and discarded to remove any cells found in the airspace prior to tissue collection for protein and mRNA extraction although BAL would not remove cells sequestered in the interstitial space. These nonresident cells may have increased NK-1R expression. The data support the authors' hypothesis that SP plays a role in the augmented immune response of mTBI mice despite similar levels of SP as TT. The increased levels of NK1R could make the mTBI lungs more sensitive to SP.

An Exogenous Mouse Chemokine and a Live Infection with Psd Increase the Pulmonary Recruitment of Neutrophils to mTBI Lungs Compared with TT

To examine whether the brain trauma primes the lung to augment immune responses, an exogenous, recombinant neutrophil chemokine CXCL1 (KC) was administered 48 hours after trauma, and mice were sacrificed 4 hours later (Figure 2). mTBI mice recruited nearly twice as many 
Table 2 Differential Counts of BAL Cells 48 Hours after TBI or TT

\begin{tabular}{llll}
\hline Trauma & Total cells $/ \mathrm{mL}$ & Neutrophils & Macrophages \\
\hline TT & $2.3 \pm 1.6 \times 10^{5}$ & 0 & $2.3 \pm 1.6 \times 10^{5}$ \\
mTBI & $1.7 \pm 0.3 \times 10^{5}$ & 0 & $1.7 \pm 0.3 \times 10^{5}$ \\
\hline
\end{tabular}

Data are expressed as means \pm SEM.

neutrophils to the lungs compared with TT mice, supporting the premise that mTBI induces beneficial changes in the lung to prepare the lungs for a bacterial challenge and increase survival. The authors' model shows an increased recruitment of neutrophils in response to an exogenous instillation of a mouse chemokine. To support the premise that mTBI recruits more pulmonary neutrophils regardless of stimulus, a live bacterial challenge was administered. mTBI mice also recruited significantly more neutrophils to the lungs compared with TT mice 4 hours after Psd challenge (Figure 3A). These data (Figures 2 and 3) support the concept that mTBI alters the lungs so that whether challenged with an exogenous chemokine or a live infection, they respond similarly and have an augmented neutrophil recruitment to both stimuli.

Increased Neutrophil Recruitment in mTBI Mice Lowers the Bacterial Burden in the Lung

Although the mTBI mice recruit more neutrophils to the lung than TT after infection, it is unclear whether the neutrophils also contribute to survival by eradicating more bacteria. To test this, the bacterial burden was determined in BAL 4 hours after Psd challenge (Figure 3B). mTBI mice showed fewer bacterial colony-forming units compared with TT mice in the BAL fluid 4 hours after Psd challenge. Bacterial invasion into the bloodstream was evaluated to determine whether mTBI induced structural alterations in the lung that allowed the translocation of bacteria from the airspace. The presence of bacteria in circulation was determined by collecting peripheral blood from the vena cava upon sacrifice 4 hours after Psd and plating it on blood agar plates (Figure 3B). Neither mTBI nor TT mice had detectable bacteria in the peripheral blood after infection, suggesting that the barrier between the airspace and bloodstream in mTBI mice is intact during infection.

\section{mTBI-Induced Broad Gene Expression Changes in Lungs 48 Hours after Trauma: Microarray GeneChip Analysis}

Brain injury has been shown to cause gene expression changes in the cerebral cortex following trauma. ${ }^{27}$ However, the gene expression changes following a brain injury have not been thoroughly explored in the lungs. The prior data demonstrated an up-regulation of NK1R mRNA and protein levels in the lungs after mTBI prompting studies of widespread changes in gene expression in the lungs after mTBI
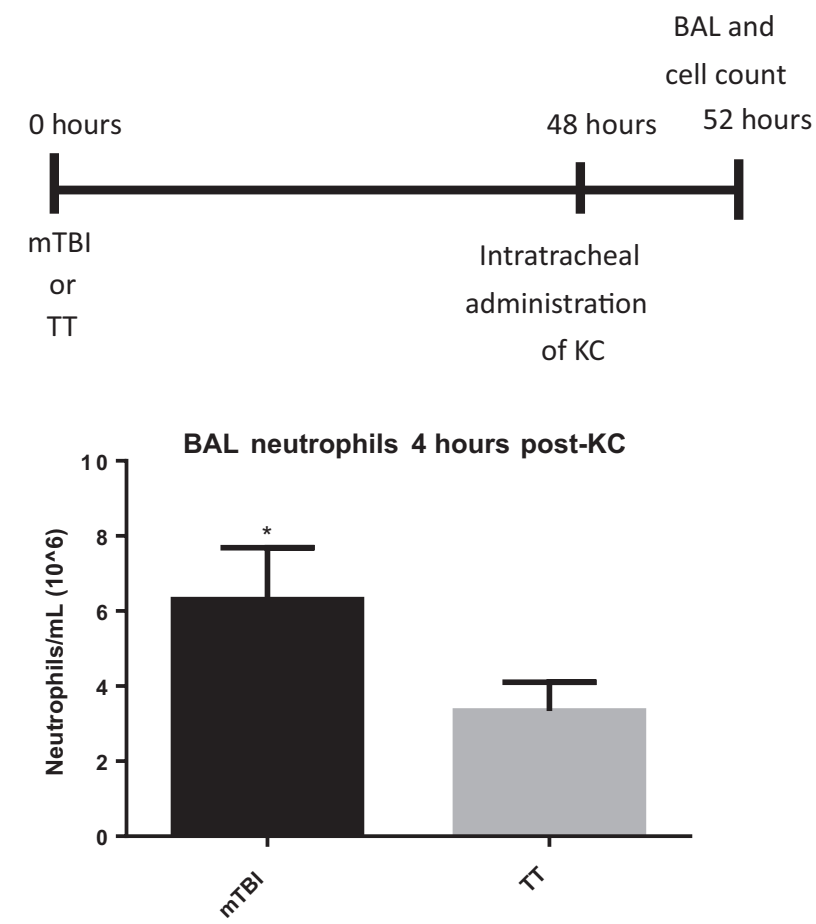

Figure 2 Increased pulmonary recruitment of neutrophils in mild traumatic brain injury (mTBI) mice. Four hours after intratracheal administration of an exogenous chemokine CXCL1 (KC) at 48 hours after trauma, cellular infiltration into the lung was analyzed in bronchoalveolar lavage (BAL) of mTBI and blunt tail trauma (TT) mice. Data are expressed as means \pm SEM. $n=5 \mathrm{mTBI}$ and TT. ${ }^{*} P<0.05$ versus TT (unpaired onetailed $t$-test).

and TT. The mTBI may have caused other alterations in the lung that could contribute to the increased survival due to a pulmonary infection. ${ }^{8,9}$ RNA was extracted 48 hours after trauma from mTBI and TT lungs and analyzed for multiple gene expression changes using microarray analysis. To better visualize the broad overall genetic differences between $\operatorname{mTBI}(n=2)$ and TT $(n=3)$ lungs at 48 hours, the results of the microarray were analyzed via PCA. PCA is a mathematic algorithm that groups the genetic differences between samples across all 21,187 probesets on the chip into smaller principal components (PC) so that larger differences can easily be demonstrated. The PC1 axis accounts for the most genetic variation. The mTBI lung RNA separated strongly from the TT samples on this axis. This separation suggests that $34 \%$ of the gene expression variance between groups is a biological consequence of the mTBI (Figure 4).

\section{Changes in Gene Expression Profile}

Up-Regulation in Gene Sets Related to ATP Synthesis

Whereas the PCA looks at broad overall genetic changes, GSEA highlights more specific changes. GSEA groups sets of genes that are coordinately up- or down-regulated with respect to a given comparison. The gene sets are related to biological pathways or processes and the genes are 


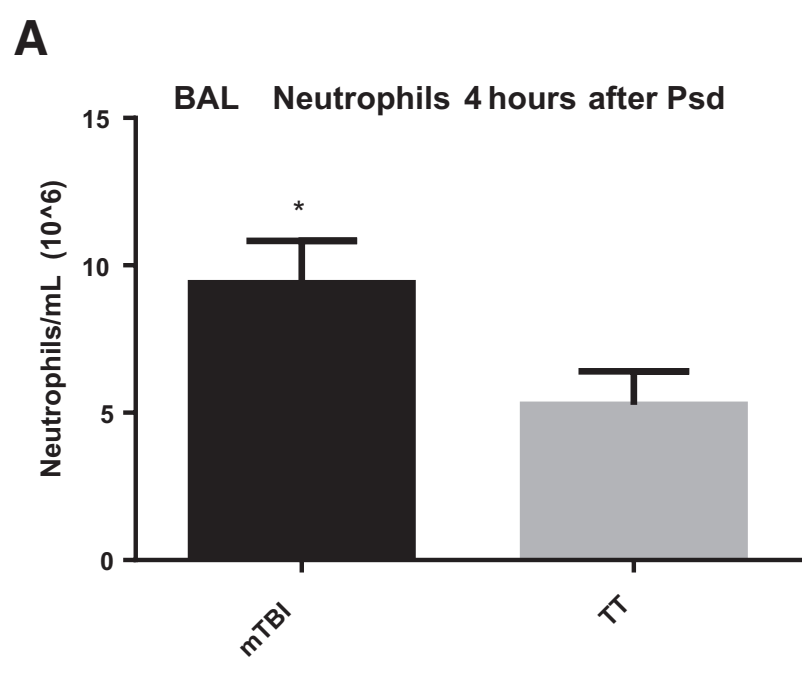

B

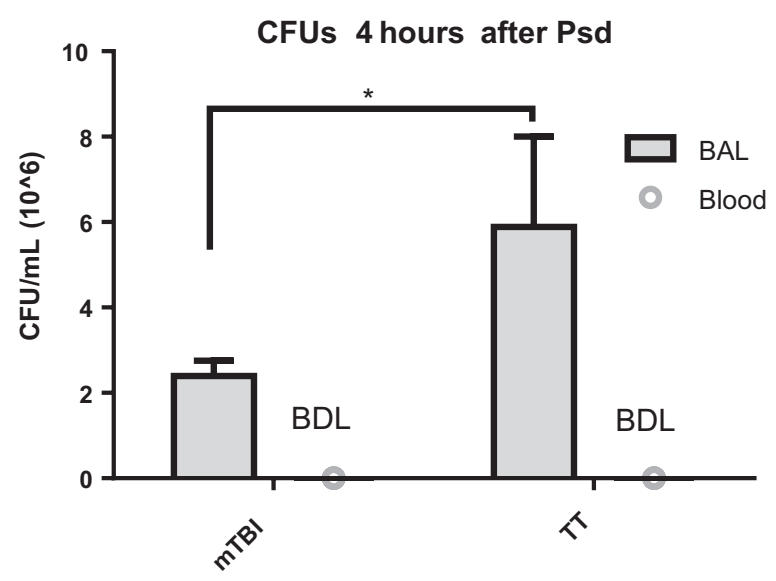

Figure 3 Increased neutrophil recruitment and decreased residual bacteria in mild traumatic brain injury (mTBI) mice in response to intratracheal administration of Pseudomonas aeruginosa (Psd). A: mTBI mice recruit more neutrophils to the airspace in response to a live infection, similar to the higher levels of neutrophils seen after administration of KC. B: Higher neutrophil numbers appear to lower the bacterial burden in the lungs of the mTBI mice. Blood collected from the vena cava upon sacrifice shows no detectable bacterial burden, suggesting the protein-level differences in mTBI mice at 48 hours does not predispose the mice to bacteremia when infected. Data are expressed as means \pm SEM. $n=8$ mTBI (A and B, BAL); $n=7$ TT (A and B, BAL); $n=6$ blood (B). ${ }^{*} P<0.05$ versus TT (unpaired one-tailed $t$-test). $B A L$, bronchoalveolar lavage; $B D L$, below detection limit; CFU, colony-forming unit.

compared with publicly available gene sets at the Molecular Signatures Database (MSigDB, http://software. broadinstitute.org/gsea/msigdb/index.jsp, last accessed July 3, 2018). Of the 433 total gene sets that had a $P<0.05$ and a FDR q $<0.25,98$ were up-regulated in mTBI compared with TT lungs. Of the 98 up-regulated gene sets, 20 are related to adenosine triphosphate (ATP) synthesis or mitochondrial structure and function (Figure 5A). The most significantly up-regulated gene sets are related to oxidative phosphorylation. The augmented message for pathways related to ATP and mitochondrial structure support the preclinical and clinical studies that show increased metabolism after brain injury. ${ }^{28-31}$ To determine whether the mTBI in this model induces a hypercatabolic state, body weight was measured in both mTBI and TT mice. Consistent with the mRNA data, mTBI mice had significant weight loss that was not observed in the TT mice (Figure 5B). The hypermetabolism documented following brain injury appears to be systemic. However, the up-regulated gene sets sourced from lung RNA suggest that an increased energetic state occurs in the lungs of the mTBI mice. This increased energy production could help augment the immune response when challenged with pneumonia 48 hours after trauma. Up-regulation of metabolic gene expression has been documented in the brain of rats shortly after brain trauma. ${ }^{32}$ Although we have not established a direct relationship between the gene expression data and enhanced immune function in the lungs, the authors' model supports this as a possibility. Following mTBI and pneumonia challenge, the increased neutrophil numbers and lower bacterial burden in mTBI lungs supports the hypothesis that the up-regulated gene sets provide more energy for an amplified immune response compared with TT mice. These findings lead us to believe that the lungs could be more energetically primed to mount a stronger response to a bacterial challenge. The increased neutrophil recruitment to the airspace after CXCL1 and Psd instilment support this hypothesis.

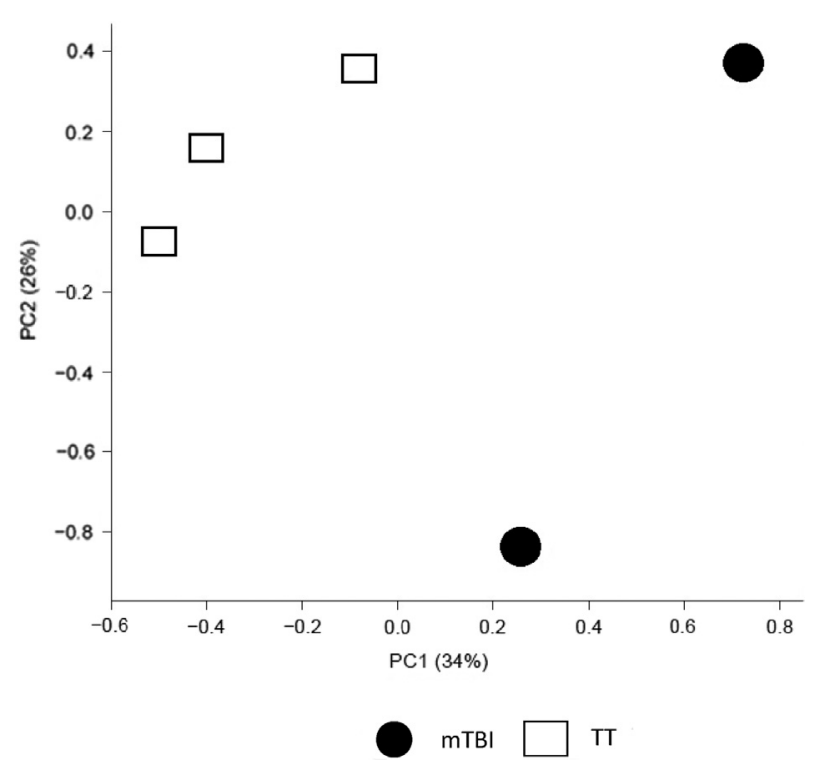

Figure 4 Plot of Principal Component (PC) 1 versus PC 2, computed across all genes. The principal component analysis plot represents the broad differences in genetic expression of mild traumatic brain injury (mTBI) and blunt tail trauma (TT) RNA extracted from mouse lungs. Treatment groups separate strongly with $34 \%$ variance on the PC1 axis, the axis that accounts for the most variation, suggesting mTBI is responsible for the gene expression changes in the lung. $n=2 \mathrm{mTBI}$; $n=3 \mathrm{TT}$. 


\section{A KEGG Oxidative phosphorylation}
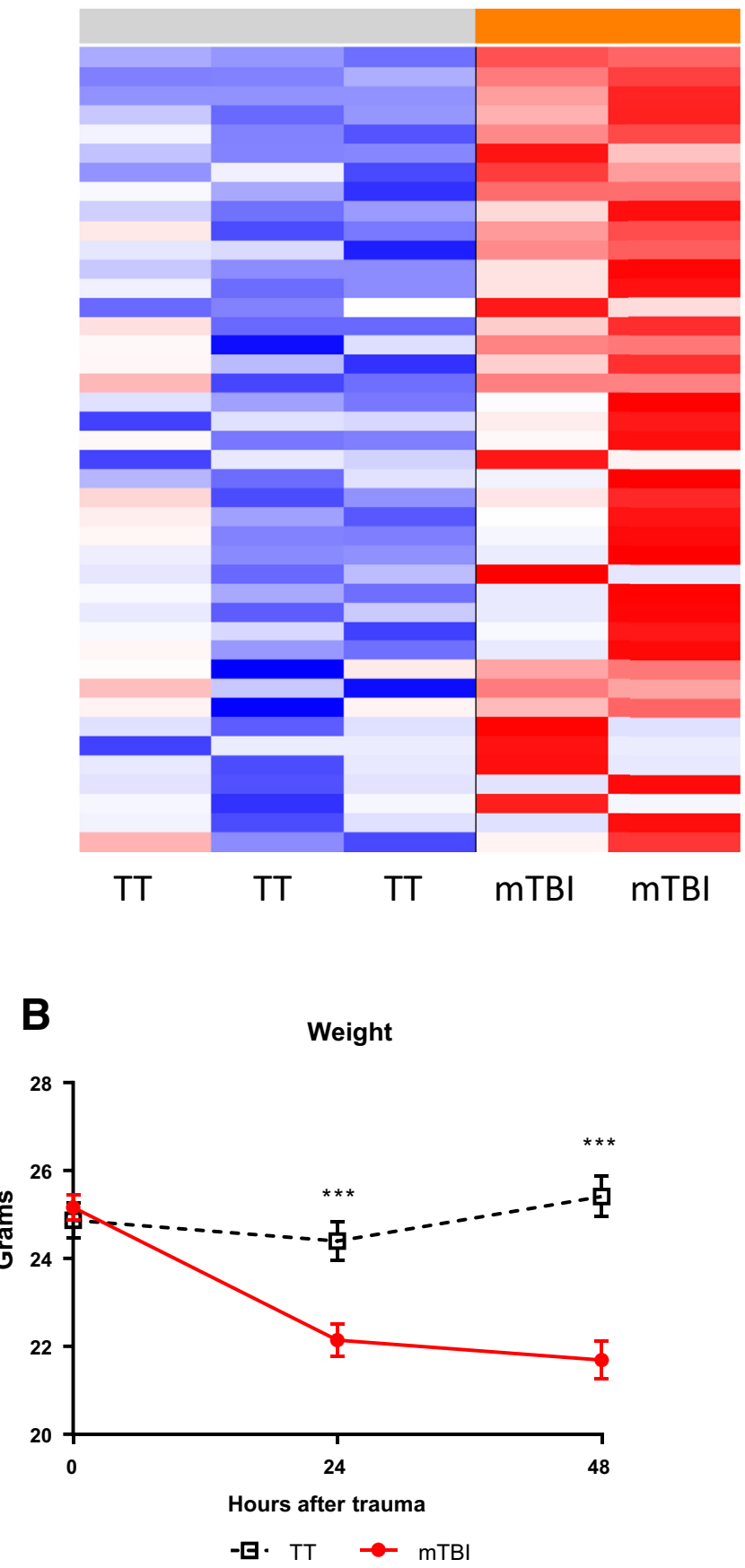

Figure 5 Representative heatmap of the gene sets up-regulated in mild traumatic brain injury (mTBI) versus blunt tail trauma (TT) within the KEGG classified Oxidative Phosphorylation set (red and blue $=$ upregulated and down-regulated compared with mean expression, respectively). A gene set that is significantly different between mTBI and TT with a $P<0.05$ and FDR $\mathrm{q}<0.25$ suggests that the pathway or process could be changed as a result of the mTBI. A: Of the 94 significantly upregulated gene sets in mTBI lungs, 20 are related to ATP synthesis and mitochondrial structure. B: Literature supports that brain injury causes a hypercatabolic state, as evidenced by the drop in weight of the mTBI group in the 2 days following trauma. Data are expressed as means \pm SEM. $n=20$ mTBI (B); $n=21$ TT (B). ${ }^{* * *} P<0.001$ versus mTBI at the corresponding time point (multiple unpaired two-tailed $t$-tests).
Down-Regulation of Intercellular Proteins, but No Histological Damage, 48 Hours after Trauma

mTBI lungs have multiple down-regulated gene sets related to intercell, intracell, and extracellular connections and organization (Figure 6A). To assess whether this mTBIinduced down-regulation could have negatively affected lung integrity, 48 hours after trauma, lungs of mTBI and TT mice were fixed for histology. The hematoxylin and eosin-stained lungs were examined by a board-certified pathologist (D.G.R.) in a blinded manner and scored for injury. ${ }^{15}$ There was no histologic evidence of damage in the lungs of mTBI or TT lungs (Figure 6, B-D). Lungs from naive mice were also examined as an additional control and showed no difference compared with both trauma groups. mTBI does not alter the structure of the lungs as compared with TT and naive lungs. This suggests that mTBI downregulates the gene expression of structural proteins but not to a level that disrupts the structural integrity of the airspace. This balance could contribute to beneficial changes that allow increased neutrophil entry to the lungs.

\section{VE Cadherin Protein Not Decreased by mTBI}

To validate the microarray data that suggest lower levels of intercell, intracell, and extracellular connection proteins, levels of gene and protein expression in mouse lung were analyzed via real-time qPCR and Western blot. An intercellular connection protein, VE-cadherin, which was downregulated on the microarray and is a protein regulating protein leak and neutrophil extravasation, was chosen. ${ }^{33-37}$ The authors hypothesized that lower levels of this protein in the lung could aid neutrophil migration once challenged with pneumonia. This suggestion is supported by studies that show increased extravasation and permeability when an anti-VE-cadherin antibody is given to mice. ${ }^{38,39}$ The gene expression levels of VE-cadherin were first analyzed using real-time qPCR (Figure 7A). This method confirmed the microarray data that suggested that VE-cadherin gene expression was lower. Next, the protein levels were analyzed to see whether they followed the VE-cadherin gene expression. Although the VE-cadherin protein levels were slightly lower, the changes were not statistically significant (Figure 7B).

Another protein also down-regulated on the microarray that is related to structural integrity, laminin, was examined via Western blot. Laminin is a component of the basement membrane and is a barrier to neutrophil migration that could be an additional contributor to the increased neutrophil extravasation seen after pneumonia challenge. Studies show that neutrophils pass through holes in the basal laminae to enter the alveolus from the capillaries, and mice lacking an isoform of laminin in endothelial basement membranes show increased neutrophil transmigration. ${ }^{40}$ Despite the predicted lower levels based on the microarray data, there was no significant difference in laminin protein concentrations between mTBI and TT (Supplemental Figure S1). 

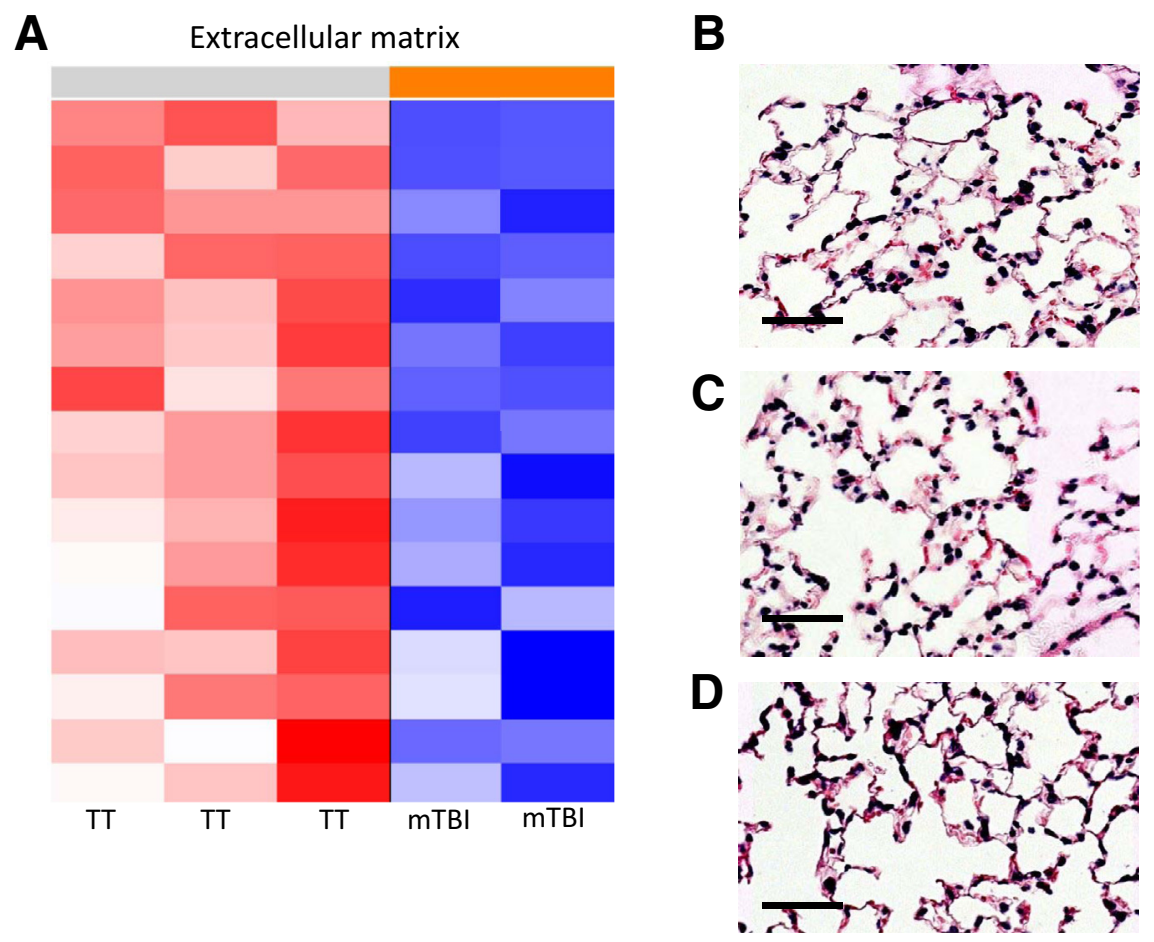

Figure 6 Representative heatmap of the gene sets down-regulated in mild traumatic brain injury (mTBI) versus blunt tail trauma (TT) lungs. A: Multiple gene sets were down-regulated in mTBI lungs related to intercell, intracell, and extracellular connections and organization. B: mTBI. C: TT. D: Naive. Although mRNA levels of extracellular proteins are decreased, there is no obvious histological structural damage. Scale bars $=50 \mu \mathrm{m}$.

\section{mTBI and TT Have Similar BAL Protein Levels as Naive Mice}

The gene expression data suggest that structural proteins are down-regulated at 48 hours. Histological analysis implies no structural differences (Figure 6, B-D). Selection of two structural proteins shows no difference in quantity (Figure 7 and Supplemental Figure S1). However, the lung is composed of many intercellular proteins, and though the authors' choices were not reduced in quantity, many others could be. To determine whether the lungs resulted in a histologically sound, but physiologically leaky, lung, more specific methods were used. Although the authors interpret the leakiness of the lungs as beneficial for neutrophil entry, it could also prove detrimental because it impedes proper pulmonary function. If multiple connective proteins have decreased expression, the BAL could contain more proteins at 48 hours, which could impede proper lung function and possibly lead to increased mortality. ${ }^{41-43}$ Because damaged lungs have higher levels of proteins in the BAL ${ }^{44-46}$ protein levels within the BAL were measured at 48 hours after trauma to assess whether what is seen as beneficial for neutrophil entry could be detrimental to the host as a whole.

To measure protein and determine lung integrity, various proteins in the BAL ranging from large to small (IgM, IgG, and albumin) were tested via ELISA. There were no significant differences in the proteins of different sizes in the BAL of mTBI, TT, or naive mice 48 hours after trauma (Supplemental Figure S2). mTBI has similar levels of protein in the BAL at 48 hours; pulmonary parameters such as oxygen saturation and respiratory rate have been shown to be equivalent between mTBI and TT shortly after trauma and return to baseline levels at 48 hours. ${ }^{8}$ The similar levels of protein in the BAL fluid suggest that the down-regulation of the intercellular proteins could allow for easier neutrophil entry without compromising lung integrity.

\section{Discussion}

Traumatic brain injuries are a serious health issue that have continuous effects on those who sustain them. ${ }^{47}$ The large number of structural and physiological changes that occur in the brain following a traumatic injury make the health consequences of a TBI substantial. ${ }^{48}$ However, although a seemingly innumerable number of molecular signaling cascades are triggered by the trauma, ${ }^{49-51}$ the entirety of the results have not been thoroughly explored for possible benefit. There are three levels of TBI: mild, moderate, and severe. The authors' research is focused on mTBI because it is the most common TBI in humans. ${ }^{52}$ Previous studies have shown that a mTBI may provide a protective effect for the host against a bacterial pneumonia challenge and has been shown to induce a "neurometabolic cascade of concussion" ${ }^{, 0}$ that releases neurotransmitters and causes fluctuations in ionic balances. Therefore, it was examined whether the mTBI model could provide a favorable balance between the detrimental and possibly beneficial effects of a brain injury, particularly in the lungs.

Central nervous system insults have an effect on the lungs in a variety of ways. Broad observations of lung dysfunction 

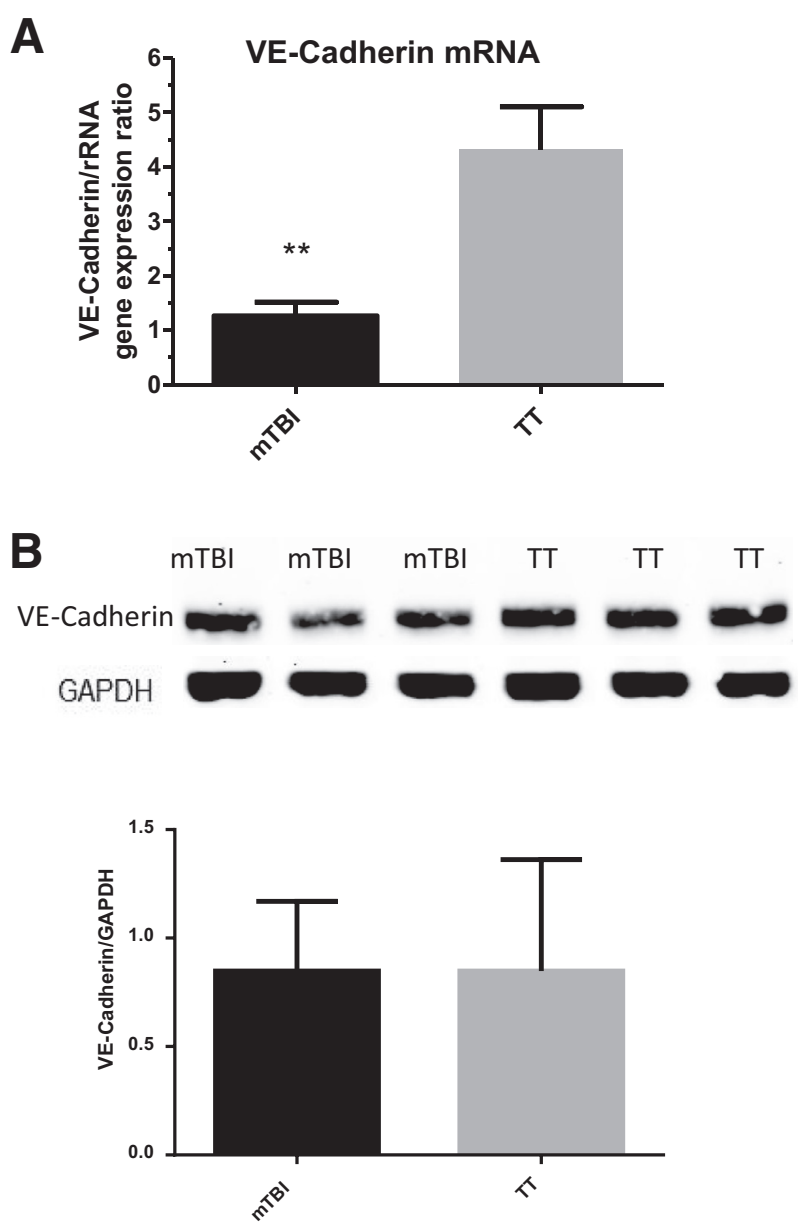

Figure 7 Pulmonary VE-cadherin gene expression and protein levels 48 hours after trauma. A: VE-cadherin gene expression is significantly downregulated in mild traumatic brain injury (mTBI) lungs 48 hours after trauma. B: VE-cadherin is detected by Western blot and the relative expression compared with GAPDH was plotted. Protein levels are marginally decreased but show no significant difference. Data are expressed as means \pm SEM. $n=5 \mathrm{mTBI}$ and TT (A); $n=12 \mathrm{mTBI}$ and TT (B). ${ }^{* *} P<0.01$ versus TT (unpaired two-tailed $t$-test).

as well as neurogenic pulmonary edema, an influx of fluid into the lungs following a central nervous system injury, have been well documented. ${ }^{53-57}$ The literature supports a central nervous system injury-pulmonary response that overall seems to result in harm to lung physiological and immunologic function. However, the severity of the head injury has an effect on the severity of response in the lung. ${ }^{58}$ The lower the severity of head injury, the more nuanced the possible beneficial response may be in the lungs, a relationship that has not been rigorously explored. The gene expression data showed down-regulation of lung mRNA, which could account for the mTBI-induced increase in pulmonary fluid $^{59}$ as well as alterations in metabolism and mitochondrial function. ${ }^{60,61}$ However, much of the literature details these changes systemically or in the brain, whereas the authors' gene expression changes were only examined in the lungs. Because the microarray suggested that far more structural proteins than VE-cadherin and laminin were down-regulated, further exploration should center on the cumulative effect on neutrophil extravasation of all the suggested structural proteins being slightly down-regulated. Importantly, whatever protein decrease there may be does not appear to affect lung integrity in the mTBI model. This is supported by the equivalent after-trauma BAL protein levels and a lack of bacteria in the peripheral blood between the two trauma groups.

With this framework of a central nervous system injury-pulmonary response established in the literature and the authors' findings, the counterintuitive observation of the beneficial effects of mTBI on pneumonia mortality may involve far more than the authors' previous exploration of the role of SP. SP has a number of characteristics that make it a prime candidate for this hypothesis. It is released following a painful stimuli similar to $\mathrm{mTBI},{ }^{8,62,63}$ it has chemotactic and immune augmenting properties, ${ }^{64-68}$ and a source of its release, the vagal nerve, innervates the lungs and likely influences permeability and the immune response. ${ }^{69-71}$ Additionally, previous work shows that blockade of the preferred SP receptor, NK1R, eliminates the increased survival of the mTBI mice. ${ }^{9}$ This finding is of interest because a Food and Drug Administration-approved antiemetic for chemotherapy, aprepitant, is an NK1R antagonist. Given the immunologically fragile state of patients receiving chemotherapy, these findings are concerning because the action of SP on its receptor may prove beneficial for proper immune function to combat infections. Patients receiving aprepitant versus placebo had increased adverse events, including serious infections, febrile neutropenia, or urinary tract infections. ${ }^{72-74}$ Another study determining the correct dosage of aprepitant noticed a higher incidence of infection (13\%) with aprepitant versus a $4 \%$ incidence in the standard therapy group. ${ }^{75}$ The study authors believe that a pharmacokinetic interaction of aprepitant with dexamethasone was causing these adverse immunological events. When a modified dexamethasone regimen was used, there were no differences in serious infection adverse events between groups, supporting this hypothesis. $^{76,77}$

This paper explores the effects of a closed-head weightdrop mTBI on murine lungs 48 hours after trauma. A number of potentially beneficial results arise from this that could better prepare the host for a bacterial infection. These changes may be advantageous as increased survival of mTBI mice compared with TT mice has been observed when challenged with Psd 48 hours after trauma. ${ }^{8,9}$ These observations are of value because across two former studies and the current one, the mTBI model has proven to be reproducible, which has emerged as an important consideration for preclinical studies. ${ }^{78} \mathrm{TBI}$ is not being advocated as a means to augment the immune system; rather, we support further exploration of the mechanisms triggered by a mTBI that appear beneficial for the immune response. Although initial evidence points toward the role of SP and 
NK1R, many mechanisms may regulate changes in certain proteins or signaling cascades in the lung. Additional work needs to be completed to explore and confirm other possible effects of mTBI on the lungs, which could better define the precise mechanisms. Some limitations of this study are the analysis of the lung occurred without pneumonia, so the effects seen at 48 hours may be short lasting once an infection takes place. This could mean that whatever changes were documented are short lived and another mechanism may account for the increased neutrophil counts and lower bacterial burden. Another limitation is the limited scope of proteins targeted. Many more proteins (as suggested by the microarray) are affected by the mTBI than NK1R, VE-cadherin, and laminin. Therefore, many other factors could explain why the mTBI mice respond to the pneumonia more robustly than TT. Additional studies could also explore the role of the changes in genes related to oxidative phosphorylation and changes in body weight. Evidence uncovering how mTBI appears to provide a protective effect to a bacterial pneumonia challenge could be harnessed as a host-derived means of immune augmentation, which may be helpful in the light of antibiotic resistance.

\section{Supplemental Data}

Supplemental material for this article can be found at https://doi.org/10.1016/j.ajpath.2018.10.019.

\section{References}

1. Voss JD, Connolly J, Schwab KA, Scher AI: Update on the epidemiology of concussion/mild traumatic brain injury. Curr Pain Headache Rep 2015, 19:32

2. Werner C, Engelhard K: Pathophysiology of traumatic brain injury. Br J Anaesth 2007, 99:4-9

3. Masel BE, DeWitt DS: Traumatic brain injury: a disease process, not an event. J Neurotrauma 2010, 27:1529-1540

4. Lucas S-M, Rothwell NJ, Gibson RM: The role of inflammation in CNS injury and disease. Br J Pharmacol 2006, 147 Suppl 1: S232-S240

5. Paterson HM, Murphy TJ, Purcell EJ, Shelley O, Kriynovich SJ, Lien E, Mannick JA, Lederer JA: Injury primes the innate immune system for enhanced Toll-like receptor reactivity. J Immunol 2003, 171:1473-1483

6. Maung AA, Fujimi S, MacConmara MP, Tajima G, McKenna AM, Delisle AJ, Stallwood C, Onderdonk AB, Mannick JA, Lederer JA: Injury enhances resistance to Escherichia coli infection by boosting innate immune system function. J Immunol 2008, 180:2450-2458

7. Southard R, Ghosh S, Hilliard J, Davis C, Mazuski C, Walton A, Hotchkiss R: Pulmonary contusion is associated with toll-like receptor 4 upregulation and decreased susceptibility to pseudomonas pneumonia in a mouse model. Shock 2012, 37:629-633

8. Hsieh T, Vaickus MH, Stein TD, Lussier BL, Kim J, Stepien DM, Duffy ER, Chiswick EL, Remick DG: The role of substance P in pulmonary clearance of bacteria in comparative injury models. Am J Pathol 2016, 186:3236-3245

9. Yang S, Stepien D, Hanseman D, Robinson B, Goodman MD, Pritts TA, Caldwell CC, Remick DG, Lentsch AB: Substance P mediates reduced pneumonia rates after traumatic brain injury. Crit Care Med 2014, 42:2092-2100

10. Regoli D, Boudon A, Fauchére JL: Receptors and antagonists for substance P and related peptides. Pharmacol Rev 1994, 46:551-599

11. Harrison S, Geppetti P: Substance P. Int J Biochem Cell Biol 2001, 33:555-576

12. Carolan EJ, Casale TB: Effects of neuropeptides on neutrophil migration through noncellular and endothelial barriers. J Allergy Clin Immunol 1993, 92:589-598

13. Roch-Arveiller M, Regoli D, Chanuad B, Lenoir M, Muntaner O, Stralzko S, Giroud JP: Tachykinins: effects on motility and metabolism of rat polymorphonuclear leucocytes. Pharmacology 1986, 33 : 266-273

14. Sun J, Ramnath RD, Bhatia M: Neuropeptide substance P upregulates chemokine and chemokine receptor expression in primary mouse neutrophils. Am J Physiol Cell Physiol 2007, 293:C696-C704

15. Iskander KN, Craciun FL, Stepien DM, Duffy ER, Kim J, Moitra R, Vaickus LJ, Osuchowski MF, Remick DG: Cecal ligation and puncture-induced murine sepsis does not cause lung injury. Crit Care Med 2013, 41:159-170

16. Hudry-Clergeon H, Stengel D, Ninio E, Vilgrain I: Platelet-activating factor increases VE-cadherin tyrosine phosphorylation in mouse endothelial cells and its association with the PtdIns3'-kinase. FASEB J 2005, 19:512-520

17. Irizarry RA, Hobbs B, Collin F, Beazer-Barclay YD, Antonellis KJ, Scherf U, Speed TP: Exploration, normalization, and summaries of high density oligonucleotide array probe level data. Biostatistics 2003, 4:249-264

18. Gautier L, Cope L, Bolstad BM, Irizarry RA: affy-analysis of Affymetrix GeneChip data at the probe level. Bioinformatics 2004, 20:307-315

19. Gentleman RC, Carey VJ, Bates DM, Bolstad B, Dettling M, Dudoit S, Ellis B, Gautier L, Ge Y, Gentry J, Hornik K, Hothorn T, Huber W, Iacus S, Irizarry R, Leisch F, Li C, Maechler M, Rossini AJ, Sawitzki G, Smith C, Smyth G, Tierney L, Yang JYH, Zhang J: Bioconductor: open software development for computational biology and bioinformatics. Genome Biol 2004, 5:R80

20. Dai M, Wang P, Boyd AD, Kostov G, Athey B, Jones EG, Bunney WE, Myers RM, Speed TP, Akil H, Watson SJ, Meng F: Evolving gene/transcript definitions significantly alter the interpretation of GeneChip data. Nucleic Acids Res 2005, 33:e175

21. Brettschneider J, Collin F, Bolstad BM, Speed TP: Quality assessment for short oligonucleotide microarray data. Technometrics 2008, $50: 241-264$

22. Benjamini Y, Hochberg Y: Controlling the false discovery rate: a practical and powerful approach to multiple testing. J R Stat Soc Series B Stat Methodol 1995, 57:289-300

23. NCBI Resource Coordinators: Database resources of the National Center for Biotechnology Information. Nucleic Acids Res 2013, 41: D8-D20

24. Subramanian A, Tamayo P, Mootha VK, Mukherjee S, Ebert BL, Gillette MA, Paulovich A, Pomeroy SL, Golub TR, Lander ES, Mesirov JP: Gene set enrichment analysis: a knowledge-based approach for interpreting genome-wide expression profiles. Proc Natl Acad Sci U S A 2005, 102:15545-15550

25. Subramanian A, Kuehn H, Gould J, Tamayo P, Mesirov JP: GSEA-P: a desktop application for gene set enrichment analysis. Bioinformatics 2007, 23:3251-3253

26. McCarson KE: Central and peripheral expression of neurokinin-1 and neurokinin-3 receptor and substance P-encoding messenger RNAs: peripheral regulation during formalin-induced inflammation and lack of neurokinin receptor expression in primary afferent sensory neurons. Neuroscience 1999, 93:361-370

27. Raghavendra Rao VL, Dhodda VK, Song G, Bowen KK, Dempsey RJ: Traumatic brain injury-induced acute gene expression changes in rat cerebral cortex identified by GeneChip analysis. J Neurosci Res 2003, 71:208-219 
28. Krakau K, Omne-Pontén M, Karlsson T, Borg J: Metabolism and nutrition in patients with moderate and severe traumatic brain injury: a systematic review. Brain Inj 2006, 20:345-367

29. Pepe JL, Barba CA: The metabolic response to acute traumatic brain injury and implications for nutritional support. J Head Trauma Rehabil 1999, 14:462-474

30. Ott L, McClain C, Young B: Nutrition and severe brain injury. Nutrition 1989, 5:75-79

31. Yoshino A, Hovda DA, Kawamata T, Katayama Y, Becker DP: Dynamic changes in local cerebral glucose utilization following cerebral concussion in rats: evidence of a hyper- and subsequent hypometabolic state. Brain Res 1991, 561:106-119

32. Matzilevich DA, Rall JM, Moore AN, Grill RJ, Dash PK: High-density microarray analysis of hippocampal gene expression following experimental brain injury. J Neurosci Res 2002, 67:646-663

33. Gavard J, Gutkind JS: VEGF controls endothelial-cell permeability by promoting the $\beta$-arrestin-dependent endocytosis of VE-cadherin. Nat Cell Biol 2006, 8:1223-1234

34. Broermann A, Winderlich M, Block H, Frye M, Rossaint J, Zarbock A, Cagna G, Linnepe R, Schulte D, Nottebaum AF, Vestweber D: Dissociation of VE-PTP from VE-cadherin is required for leukocyte extravasation and for VEGF-induced vascular permeability in vivo. J Exp Med 2011, 208:2393-2401

35. Lim MJ, Chiang ET, Hechtman HB, Shepro D: Inflammation-induced subcellular redistribution of VE-cadherin, actin, and $\gamma$-catenin in cultured human lung microvessel endothelial cells. Microvasc Res 2001, 62:366-382

36. Golovkine G, Faudry E, Bouillot S, Voulhoux R, Attrée I, Huber P: VE-cadherin cleavage by LasB protease from Pseudomonas aeruginosa facilitates type III secretion system toxicity in endothelial cells. PLoS Pathog 2014, 10:e1003939

37. Dejana E, Vestweber D: The role of VE-cadherin in vascular morphogenesis and permeability control. Prog Mol Biol Transl Sci 2013, 116:119-144

38. Corada M, Mariotti M, Thurston G, Smith K, Kunkel R, Brockhaus M, Lampugnani MG, Martin-Padura I, Stoppacciaro A, Ruco L, McDonald DM, Ward PA, Dejana E: Vascular endothelial-cadherin is an important determinant of microvascular integrity in vivo. Proc Natl Acad Sci U S A 1999, 96:9815-9820

39. Gotsch U, Borges E, Bosse R, Boggemeyer E, Simon M, Mossmann H, Vestweber D: VE-cadherin antibody accelerates neutrophil recruitment in vivo. J Cell Sci 1997, 110(Pt 5):583-588

40. Walker DC, Behzad AR, Chu F: Neutrophil migration through preexisting holes in the basal laminae of alveolar capillaries and epithelium during streptococcal pneumonia. Microvasc Res 1995, 50:397-416

41. Holm BA, Enhorning G, Notter RH: A biophysical mechanism by which plasma proteins inhibit lung surfactant activity. Chem Phys Lipids 1988, 49:49-55

42. Martínez Sarrasague M, Cimato A, Rubin de Celis E, Facorro G: Influence of serum protein and albumin addition on the structure and activity of an exogenous pulmonary surfactant. Respir Physiol Neurobiol 2011, 175:316-321

43. Chen G-S, Huang K-F, Huang C-C, Wang J-Y: Thaliporphine derivative improves acute lung injury after traumatic brain injury. Biomed Res Int 2015, 2015:729831

44. Attia EF, Jolley SE, Crothers K, Schnapp LM, Liles WC: Soluble vascular cell adhesion molecule-1 (sVCAM-1) is elevated in bronchoalveolar lavage fluid of patients with acute respiratory distress syndrome. PLoS One 2016, 11:e0149687

45. Bhargava M, Wendt C: Biomarkers in acute lung injury. Transl Res 2012, 159:205-217

46. Orfanos SE, Mavrommati I, Korovesi I, Roussos C: Pulmonary endothelium in acute lung injury: from basic science to the critically ill. Intensive Care Med 2004, 30:1702-1714

47. Thurman DJ, Alverson C, Dunn KA, Guerrero J, Sniezek JE: Traumatic brain injury in the United States: a public health perspective. J Head Trauma Rehabil 1999, 14:602-615
48. Donkin JJ, Turner RJ, Hassan I, Vink R: Substance P in traumatic brain injury. Prog Brain Res 2007, 161:97-109

49. Barkhoudarian G, Hovda DA, Giza CC: The molecular pathophysiology of concussive brain injury. Clin Sports Med 2011, 30:33-48, vii-iii

50. Giza CC, Hovda DA: The neurometabolic cascade of concussion. J Athl Train 2001, 36:228-235

51. Barrett EC, McBurney MI, Ciappio ED: $\omega-3$ fatty acid supplementation as a potential therapeutic aid for the recovery from mild traumatic brain injury/concussion. Adv Nutr 2014, 5:268-277

52. Mckee AC, Daneshvar DH: The neuropathology of traumatic brain injury. Handb Clin Neurol 2015, 127:45-66

53. Colice GL, Matthay MA, Bass E, Matthay RA: Neurogenic pulmonary edema. Am Rev Respir Dis 1984, 130:941-948

54. Bekemeyer WB, Pinstein ML: Neurogenic pulmonary edema: new concepts of an old disorder. South Med J 1989, 82:380-383

55. Carlson RW, Schaeffer RC, Michaels SG, Weil MH: Pulmonary edema following intracranial hemorrhage. Chest 1979, 75:731-734

56. Demling R, Riessen R: Pulmonary dysfunction after cerebral injury. Crit Care Med 1990, 18:768-774

57. Baigelman W, O'Brien JC: Pulmonary effects of head trauma. Neurosurgery 1981, 9:729-740

58. Bratton SL, Davis RL: Acute lung injury in isolated traumatic brain injury. Neurosurgery 1997, 40:707-712

59. Mackersie RC, Christensen JM, Pitts LH, Lewis FR: Pulmonary extravascular fluid accumulation following intracranial injury. J Trauma 1983, 23:968-975

60. Nilsson P, Hillered L, Pontén U, Ungerstedt U: Changes in cortical extracellular levels of energy-related metabolites and amino acids following concussive brain injury in rats. J Cereb Blood Flow Metab 1990, 10:631-637

61. Vagnozzi R, Marmarou A, Tavazzi B, Signoretti S, Di Pierro D, Del Bolgia F, Amorini AM, Fazzina G, Sherkat S, Lazzarino G: Changes of cerebral energy metabolism and lipid peroxidation in rats leading to mitochondrial dysfunction after diffuse brain injury. J Neurotrauma 1999, 16:903-913

62. Cao YQ, Mantyh PW, Carlson EJ, Gillespie AM, Epstein CJ, Basbaum AI: Primary afferent tachykinins are required to experience moderate to intense pain. Nature 1998, 392:390-394

63. De Felipe CD, Herrero JF, O'Brien JA, Palmer JA, Doyle CA, Smith AJH, Laird JMA, Belmonte C, Cervero F, Hunt SP: Altered nociception, analgesia and aggression in mice lacking the receptor for substance P. Nature 1998, 392:394-397

64. Serra MC, Bazzoni F, Della Bianca V, Greskowiak M, Rossi F: Activation of human neutrophils by substance P. Effect on oxidative metabolism, exocytosis, cytosolic $\mathrm{Ca} 2+$ concentration and inositol phosphate formation. J Immunol 1988, 141:2118-2124

65. Haines KA, Kolasinski SL, Cronstein BN, Reibman J, Gold LI, Weissmann G: Chemoattraction of neutrophils by substance P and transforming growth factor-beta 1 is inadequately explained by current models of lipid remodeling. J Immunol 1993, 151:1491-1499

66. Perianin A, Snyderman R, Malfroy B: Substance P primes human neutrophil activation: a mechanism for neurological regulation of inflammation. Biochem Biophys Res Commun 1989, 161:520-524

67. Kuo HP, Lin HC, Hwang KH, Wang CH, Lu LC: Lipopolysaccharide enhances substance P-mediated neutrophil adherence to epithelial cells and cytokine release. Am J Respir Crit Care Med 2000, 162: 1891-1897

68. DeRose V, Robbins RA, Snider RM, Spurzem JR, Thiele GM, Rennard SI, Rubinstein I: Substance P increases neutrophil adhesion to bronchial epithelial cells. J Immunol 1994, 152:1339-1346

69. Gamse R, Lembeck F, Cuello AC: Substance P in the vagus nerve. Immunochemical and immunohistochemical evidence for axoplasmic transport. Naunyn Schmiedebergs Arch Pharmacol 1979, 306:37-44

70. Levy G, Fishman JE, Xu D, Dong W, Palange D, Vida G, Mohr A, Ulloa L, Deitch EA: Vagal nerve stimulation modulates gut injury 
and lung permeability in trauma-hemorrhagic shock. J Trauma Acute Care Surg 2012, 73:338-342

71. Grønstad KO, DeMagistris L, Dahlström A, Nilsson O, Price B, Zinner MJ, Jaffe BM, Ahlman H: The effects of vagal nerve stimulation on endoluminal release of serotonin and substance $\mathrm{P}$ into the feline small intestine. Scand J Gastroenterol 1985, 20:163-169

72. Dando TM, Perry CM: Aprepitant: a review of its use in the prevention of chemotherapy-induced nausea and vomiting. Drugs 2004, 64:777-794

73. de Wit R, Herrstedt J, Rapoport B, Carides AD, Carides G, Elmer M, Schmidt C, Evans JK, Horgan KJ: Addition of the oral NK1 antagonist aprepitant to standard antiemetics provides protection against nausea and vomiting during multiple cycles of cisplatin-based chemotherapy. J Clin Oncol 2003, 21:4105-4111

74. Schmoll HJ, Aapro MS, Poli-Bigelli S, Kim H-K, Park K, Jordan K, von Pawel J, Giezek H, Ahmed T, Chan CY: Comparison of an aprepitant regimen with a multiple-day ondansetron regimen, both with dexamethasone, for antiemetic efficacy in high-dose cisplatin treatment. Ann Oncol 2006, 17:1000-1006

75. Chawla SP, Grunberg SM, Gralla RJ, Hesketh PJ, Rittenberg C, Elmer ME, Schmidt C, Taylor A, Carides AD, Evans JK, Horgan KJ:
Establishing the dose of the oral NK1 antagonist aprepitant for the prevention of chemotherapy-induced nausea and vomiting. Cancer 2003, 97:2290-2300

76. Poli-Bigelli S, Rodrigues-Pereira J, Carides AD, Julie Ma G, Eldridge K, Hipple A, Evans JK, Horgan KJ, Lawson F; Aprepitant Protocol 054 Study Group: Addition of the neurokinin 1 receptor antagonist aprepitant to standard antiemetic therapy improves control of chemotherapy-induced nausea and vomiting. Results from a randomized, double-blind, placebo-controlled trial in Latin America. Cancer 2003, 97:3090-3098

77. Hesketh PJ, Grunberg SM, Gralla RJ, Warr DG, Roila F, de Wit R, Chawla SP, Carides AD, Ianus J, Elmer ME, Evans JK, Beck K, Reines S, Horgan KJ; Aprepitant Protocol 054 Study Group: The oral neurokinin-1 antagonist aprepitant for the prevention of chemotherapy-induced nausea and vomiting: a multinational, randomized, double-blind, placebo-controlled trial in patients receiving high-dose cisplatin-The Aprepitant Protocol 052 Study Group. J Clin Oncol 2003, 21:4112-4119

78. Hsieh T, Vaickus MH, Remick DG: Enhancing scientific foundations to ensure reproducibility: a new paradigm. Am J Pathol 2018, 188:6-10 